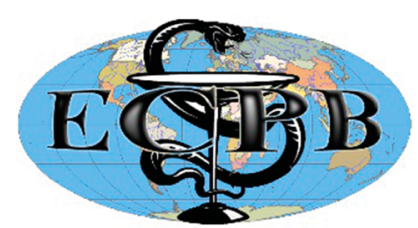

UDC 617.58-002.44-085
“ЕКСПЕРИМЕНТАЛЬНА ТА КЛІНІЧНА ФІЗІОЛОГІЯ І БІОХІМІЯ”

"EXPERIMENTAL AND CLINICAL PHYSIOLOGY AND BIOCHEMISTRY"

Науково-практичний журнал/Scientific-practical journal

\title{
Successful treatment of multiple chronic leg wounds - a case report
}

\author{
I.R. TERLETSKYI ${ }^{2}$, Y.H. OREL ${ }^{1}$, M.R. VERKHOLA ${ }^{2}$, M. M. ANTONIV ${ }^{2}$ \\ ${ }^{1}$ Danylo Halytsky Lviv National Medical University, Lviv, Ukraine \\ ${ }^{2}$ Lviv Regional Clinical Hospital, Lviv, Ukraine
}

\section{E-mail: teriva86@gmail.com}

Chronic wounds constitute a significant challenge confronting patients and health care professionals. In the USA approximately 5.7 million patients are currently suffering from chronic wounds. Expenses on their treatment are estimated at $\$ 20$ billion annually [1,2].

Lower-extremities ulcers, especially in individuals older than 65 years, are a frequent cause for attending a podiatrist, wound care specialist, primary care physician, vascular surgeon or dermatologist.

The bulk of vascular leg ulcers is chronic or recurrent. They can present significant complications among patients with the peripheral vascular disease, including work incapacity. The management of vascular leg ulcers puts a considerable burden on a patient and the health care system. Moreover, these non-healing ulcers increase the risk for lower extremity amputation [3].

Vascular leg ulcers are often multifactorial and can be caused by both arterial and venous diseases. Hypertension and atherosclerosis of peripheral vessels lead to the arterial disease associated with ischemic ulcers. In some cases, difficulties with determining the underlying cause of wound formation complicates treatment and prevents the recurrences.

Systemic sclerosis (or scleroderma) is a rare autoimmune connective tissue disorder which is associated with a various degree of systemic manifestations [4]. The organs most frequently affected by scleroderma are skin, gastrointestinal tract, lungs, kidneys, skeletal muscle, and pericardium [5].

One of the challenging complications of systemic sclerosis are non-digital lower extremity ulcers seen both in limited and diffuse scleroderma, with not exactly clear etiology that tends to reflect chronic vasculopathy. They aggravate some pain and ability of the advanced disease. As the incidence of nonhealing lower extremity ulcers in scleroderma has not specifically been studied, more researches are considered to be appropriate in this field of study.

The delayed wound healing is typical for systemic sclerosis and, likewise in other chronic leg ulcers, characterized by multifactorial etiology. A role of vascular disease has been proposed, but in spite of restoring the good blood flow and venous drainage, many scleroderma ulcers still remain refractory $[6,7]$.

The 73-year-old female patient V. was sent to the surgical department № 1 of Lviv regional clinical hospital in 2013 due to ulcers on both legs, which she developed 3 years before the clinical attendance.

Her medical history was remarkable for myocardial infarction which she suffered in 2009. She suffered from atrial fibrillation (treated by Varfarin $5 \mathrm{mg}$ ) and hypertension (treated by Valsartan $80 \mathrm{mg}$ plus Hydrochlorothiazide

(c) Terletskyi I.R., Orel Y.H., Verkhola M.R., Antoniv M.M., 2019 
$12.5 \mathrm{mg}$ ). 30 years ago the above mentioned patient underwent the surgical elimination of superficial varicose veins.

During the examination, 4 ulcers were found on the left lower leg, the wound measurements varied from 5 to $8 \mathrm{~cm}^{2}$. On the right lower leg there were another 3 ulcers (measurements varied from 4 to $22 \mathrm{~cm}^{2}$ ), one of which provoked terrible pain and forced the patient to seek some medical attention.

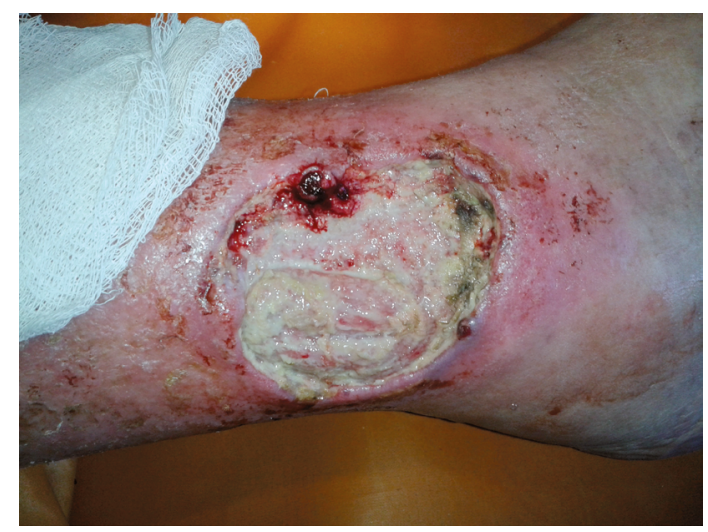

Fig. 1. Chronic ulcer on the right leg. The wound $-22 \mathrm{~cm}^{2}$

The ulcer on the mid-upper right lower leg was located above the front edge of the tibia. During the examination, one part of bone tissue-like consistency fragments of wounds was removed, another fragments could not be removed because of their motionless. The X-ray of both lower limbs was performed because some bone destruction was suspected. The X-ray showed similar fragments on the other wounds. The fragments interpreted as sclerotic modification in adipose tissue and lymphatic vessels.

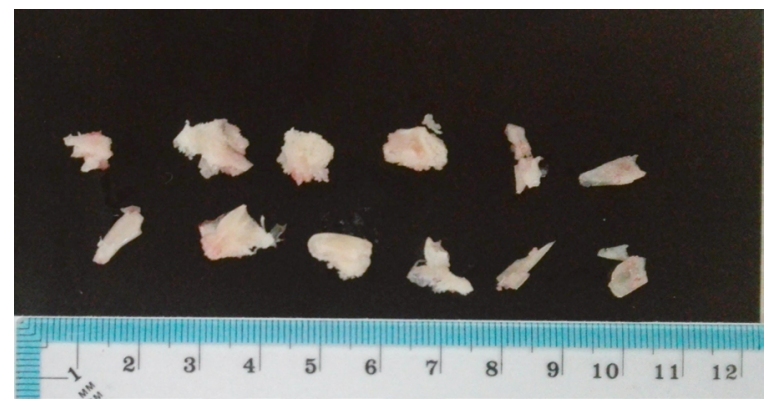

Fig. 2. Fragments removed from wounds.

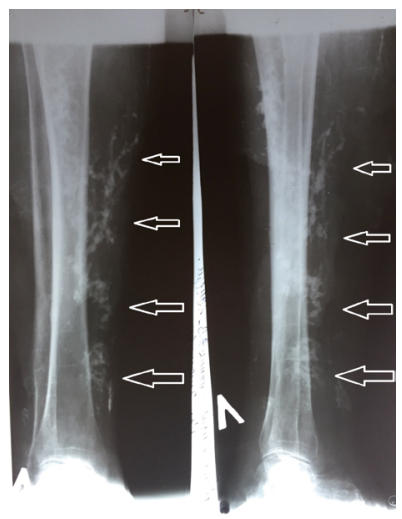

Fig. 3. The X-ray of both lower limbs. 
As a result of some additional medical examination, systemic sclerosis, Raynaud's syndrome (with typical clinical manifestation but without fingers and toes destruction) and Parkinson's disease were diagnosed. The patient refused from glucocorticoids therapy.

In addition, the patient suffered from intermittent claudication after 300$400 \mathrm{~m}$ of walking.

By using Duplex sonography, we observed $60 \%$ stenosis of the right posterior tibial artery, left anterior tibial artery occlusion, $70 \%$ stenosis of the left posterior tibial artery and the same degree stenosis of the left anterior tibial artery. Pathologic reflux was superficial and deep veins were not detected.

The patient was treated with painkillers, antibiotics, iloprost trometamol, cilostazol (the medication was discontinued because of severe headache), verapamil. Debridement of necrotic tissue enclosing the ulcer area was carried out. To promote wound healing vacuum-assisted closure therapy was used.

Removing of sclerotic-modified fragments from wounds resulted in spreading the tissue necrosis. After the termination of tissue destruction and beginning of proliferation phase, auto-dermoplasty of the largest wound of the right lower limb was performed. The healing of the other wounds was achieved through marginal epithelialization.

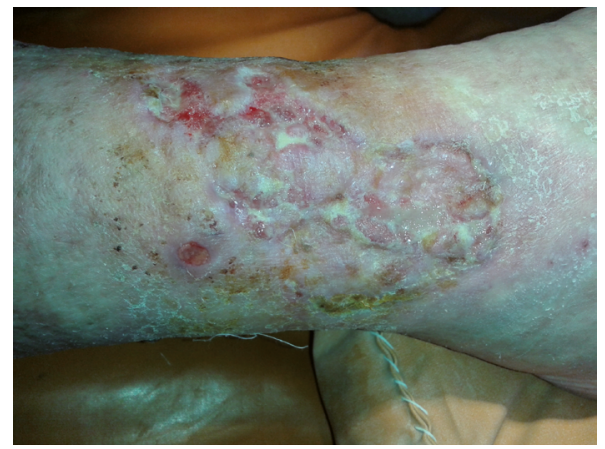

Fig. 4. The wound after the skin grafting.

The patient was sent to hospital second times during 4 months with recurrence of leg ulcers and appearance of 12 new ulcers of both lower limbs. Within the wound area, where sclerotic lesions protruded off the face surface, ischemic regions and, eventually, necrosis formation and subsequently ulcer development were observed. The patient received the same treatment and left hospital with better health condition. However, later, there were 5 more attendance with recurrent leg ulcers.

In 2016, chronic ulcer on her lower left posterior tibial region complicated by phlegmon which was dissected with removing the necrotic tissues. After purification of the wounds, auto-dermoplasty with subsequent vacuum-assisted dressing was performed. The patient left hospital with a healed wound.

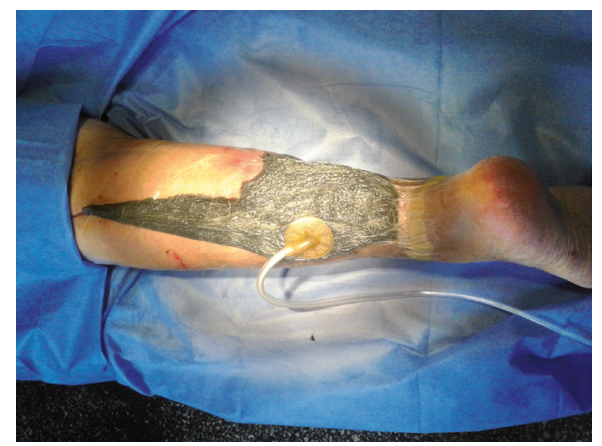

Fig. 5. Vacuum-assisted dressing on the skin graft. 
Five months later (in September 2016) the patient was sent to hospital again with multiple ulcers of both lower limbs. A total of 13 wounds on the left lower limb were the dominant problem and increasingly worsened her quality of life. During the examination, it was noticed that the only region free from ulcers was located within the area of previously phlegmon dissection. Taking into account the large quantity of leg ulcers and continual wound growth and the absence of positive effect of the conservative treatment, the extensive removal of necrotic lesions within the ulcers and sclerotic-modified tissue with further auto-dermoplasty (performed in one week after the first step of treatment) were warranted. The wound healing was achieved.

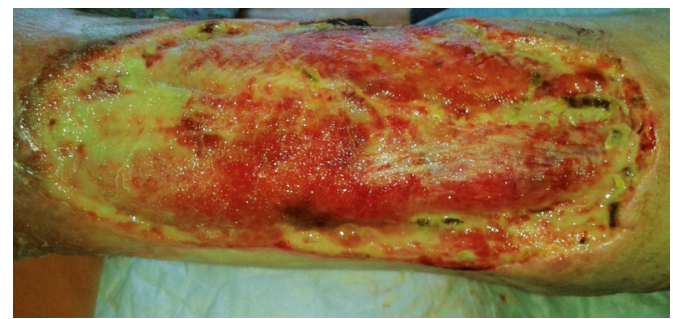

Fig. 6. Six days after debridement of the wound.

In six months the recurrence of leg ulcers was not observed. However, at that time 12 ulcers on the right lower limb still existed. The patient was suggested the same treatment (but this time auto-dermoplasty was performed simultaneous after sclerotic tissue removal). The total wound epithelialization was noted in three weeks. In the following two years the recurrence of leg ulcers was not observed.

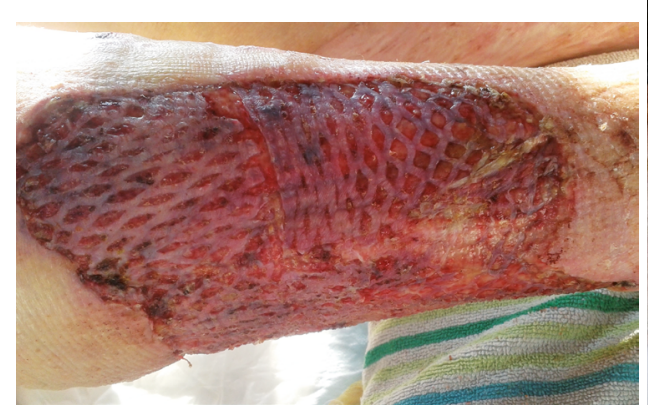

A.

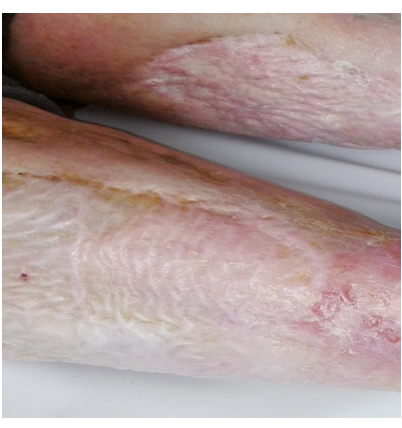

B.

Fig. 7. A. The wound after the auto-dermoplasty. B. Healed wounds.

\section{REFERENCES}

1. Branski LK, Gauglitz GG, Herndon DN, Jeschke MG. A review of gene and stem cell therapy in cutaneous wound healing. Burns. 2009 Mar;35(2):171-80. URL: doi:10.1016/j. burns.2008.03.009.

2. Frykberg RG, Banks J. Challenges in the Treatment of Chronic Wounds. Advanced Wound Care (New Rochelle). 2015;4(9):560-582. URL: doi:10.1089/wound.2015.0635.

3. Xie T, Ye J, Rerkasem K, Mani R. The venous ulcer continues to be a clinical challenge: an update. Burns Trauma. 2018;6:18. Published 2018 June 15. URL: doi:10.1186/s41038-018-0119-y.

4. Coentro JQ, Pugliese E, Hanley G, Raghunath M, Zeugolis DI. Current and upcoming therapies to modulate skin scarring and fibrosis. Adv Drug Deliv Rev. 2018 Aug 30. pii: S0169409X(18)30207-2. URL: doi:10.1016/j.addr.2018.08.009.

5. Politikou O, Giesen T, Reissner L, Calcagni M. Hand and wrist joint procedures in patients with scleroderma: a systematic review. J Hand Surg Eur. 2019 May;44(4):402-7. URL: doi: 10.1177/1753193418795632.

6. Alivernini S, De Santis M, Tolusso B, Mannocci A, Bosello SL, Peluso G et al. Skin ulcers in systemic sclerosis: determinants of presence and predictive factors of healing. J Am Acad Dermatol. 2009 Mar;60(3):426-35. URL: doi: 10.1016/j.jaad.2008.11.025.

7. Hafner J, Schneider E, Burg G, Cassina PC. Management of leg ulcers in patients with 
rheumatoid arthritis or systemic sclerosis: the importance of concomitant arterial and venous disease. J Vasc Surg. 2000 Aug;32(2):322-9.

Стаття надійшла до редколегії 24.04.2019

\title{
CLINICAL CASE REPORT
}

\section{Successful Treatment of Multiple Chronic Leg Wounds - a Case Report}

\author{
I.R. TERLETSKYI ${ }^{2}$, Y.H. OREL ${ }^{1}$, M.R. VERKHOLA ${ }^{2}$, M.M. ANTONIV ${ }^{2}$ \\ ${ }^{1}$ Danylo Halytski Lviv National Medical University, Department of Surgery 2, Lviv, Ukraine \\ ${ }^{2}$ Lviv Regional Clinical Hospital, Lviv, Ukraine \\ E-mail: teriva86@gmail.com
}

Inroduction. Lower-extremities ulcers, especially in individuals older than 65 years, are frequent cause for attending the podiatrist, wound care specialist, primary care physician, vascular surgeon or dermatologist. The bulk of vascular leg ulcers are chronic or recurrent. They can present significant complications among patients with peripheral vascular disease, including job incapacity. The management of vascular leg ulcers becomes a considerable burden to the patients and the health care system. Moreover, these non-healing ulcers increase the risk of lower extremity amputation.

The systemic sclerosis (or scleroderma) is a rare autoimmune connective tissue disorder which is associated with a various degree of systemic manifestations. The organs most frequently affected by scleroderma are the skin, gastrointestinal tract, lungs, kidneys, skeletal muscle and pericardium. One of the challenging complications of systemic sclerosis is non-digital lower extremity ulcers both in limited and diffuse scleroderma, with not exactly clear etiology but with the reflection of chronic vasculopathy.

The purpose. As the cases of nonhealing lower extremity ulcers in scleroderma have not specifically been studied, more researches are considered to be carried out.

Materials and methods. The 73-year-old female patient V. was taken to the surgical department №1 of Lviv regional clinical hospital in 2013 due to ulcers on both legs, which had been developed 3 years before the clinic attendance. During the examination 4 ulcers were found on the left lower leg, the wound measurements varied from 5 to $8 \mathrm{~cm} 2$. On the right lower leg there were another 3 ulcers (from 4 to $22 \mathrm{~cm} 2$ ), one of which caused severe pain and forced the patient to seek medical treatment. After the examination, one part of bone tissue-like consistency fragments of the wound was removed while other fragments could not be removed because of their motionless. The fragments were interpreted as the sclerotic modification in the adipose tissue and lymphatic vessels.

As a result of the additional medical examination the systemic sclerosis, Raynaud's syndrome (with typical clinical manifestation but without fingers and toes destruction) and Parkinson's disease were diagnosed. The patient refused from the glucocorticoids therapy.

In addition, the patient suffered from the intermittent claudication after $300-400 \mathrm{~m}$ of walking.

Results. By using Duplex sonography, we observed $60 \%$ stenosis of the right posterior tibial artery, left anterior tibial artery occlusion, $70 \%$ stenosis of the left posterior tibial artery and the same degree of stenosis of the left anterior tibial artery. The pathological reflux in superficial and deep veins was not detected.

Conclusions. The process of medical treatment was very difficult and lasted for three years. The total wound epithelialization was noted after the massive debridement with the further auto-dermoplasty.

Key words: wound, ulcer, chronic, treatment. 